\section{Socio-demographic characteristics, treatment coverage, and self-rated health of individuals who reported six chronic diseases in Brazil, 2003}

\author{
Características sócio-demográficas, cobertura \\ de tratamento e auto-avaliação da saúde \\ dos indivíduos que referiram seis doenças \\ crônicas no Brasil, 2003
}

Mariza Miranda Theme-Filha 1

Célia Landmann Szwarcwald 2

Paulo Roberto Borges de Souza-Júnior 2
${ }^{1}$ Escola Nacional de Saúde Pública Sergio Arouca, Fundação Oswaldo Cruz, Rio de Janeiro, Brasil.

2 Centro de Informação Científica e Tecnológica Fundação Oswaldo Cruz, Rio de Janeiro, Brasil.

Correspondence C. L. Szwarcwald Departamento de Informações em Saúde Centro de Informação Científica e Tecnológica, Fundação Oswaldo Cruz. Av. Brasil 4365,

Rio de Janeiro, $R J$ 21045-900, Brasil. celials@cict.fiocruz.br

\section{Abstract}

The Brazilian World Health Survey, carried out in 2003, included questions about diagnosis of six chronic diseases: arthritis, angina, asthma, depression, schizophrenia and diabetes mellitus. The probabilistic sample of 5,000 adults was selected in 250 census tracts. We analyzed the sociodemographic profile, the coverage of treatment, and self-rated health of the individuals that reported diagnosis of one of these diseases. To control for age and sex, logistic regression models were used. Among the 5,000 participants, 39.1\% reported medical diagnosis of at least one of the six diseases. Depression was the most prevalent (19.2\%), followed by asthma (12.0\%), arthritis (10.5\%), angina (6.7\%), diabetes (6.2\%) and schizophrenia (1.7\%). Significant differences by age were found for all diseases, except for asthma. All diseases were more prevalent among women, except angina. Analysis by educational level showed that the diabetes prevalence rate was significantly larger among those with incomplete schooling. Although the six diseases presented different treatment coverage rates, for individuals with diagnosis of any one of the six diseases, the self-rated health was always worst, even after controlling for age and sex.

Health Status; Chronic Disease; Health Services Coverage

\section{Introduction}

The theory of epidemiologic transition revolves around the complex transformation of health and disease standards and its interaction with demographic, economic, and social determinants. Although this theory is subject to criticism by some authors 1 , a historic vision of the epidemiologic transition allows the identification of certain peculiar variations in this process, that can be represented by three different models, which differ by the speed which the transformations occur in the population dynamics and in the health of various countries: the classic model - characterized by the slow and progressive transition which accompanied the modernization process in most European countries; the accelerated transition - principally represented by Japan, in which, after recovering from great pandemics, demonstrated a rapid drop in mortality; and the contemporary or prolonged model, relatively new and yet to be completed, in which a substantial drop in mortality was only registered after World War II, as observed in developing countries, including Brazil. Basically, the process of epidemiologic transition, independent of the model framing it, accounts for three basic changes: the drop in mortality, the change from communicable diseases to non-communicable diseases, and the displacement of the morbi-mortality to a more elderly age group 2 . 
The epidemiologic transition in Brazil has been characterized by an overlapping of stages in which non-communicable diseases still predominate but a significant growth in the chronic-degenerative ailments occur. Allied to this profile is the population's progressive aging, in function of mortality's and fecundity's reduction. A study of burden of disease done in Brazil in 1998 revealed that $66.3 \%$ of the DALY indicator (disability adjusted life years) were due to non-communicable diseases, $23.5 \%$ to infectious, parasitic, perinatal, maternal, and nutritional diseases, and $10.2 \%$ to external causes. In the non-communicable disease group, neuropsychiatric disorders occupied first place (18.6\%), followed by cardiovascular diseases (13.3\%), chronic respiratory diseases $(8.1 \%)$, musculo-skeletal diseases (5.5\%), and diabetes mellitus $(5.1 \%)$, creating a similar epidemiologic model to developed countries 3 . These are diseases that cause a considerable degree of suffering, pain, and disability, besides causing much burden on health services. In addition, by assaulting an economically active population, they impact performance in work and productivity $4,5,6$.

In view of the chronic non-communicable diseases' magnitude in the Brazilian population's morbi-mortality profile and the need for greater understanding over such ailments and their risk factors, the Ministry of Health (Ministério da Saúde) instituted the National Subsystem for Surveillance of Non-communicable Diseases and Ailments (SIDANT; Subsistema Nacional de Vigilância das Doenças e Agravos não Transmissíveis). SIDANT is part of the National System for Epidemiologic and Environmental Surveillance in Health (Sistema Nacional de Vigilância Epidemiológica e Ambiental em Saúde), and, as one of its various functions, recommends and adopts prevention measures that contribute to minimizing damages in risk factors of health for the following disease groups: cardio and cerebrovascular diseases, diabetes mellitus, cancer, mental illnesses, and ailments derived by external causes (Fundação Nacional de Saúde, Ministério da Saúde. Instrução Normativa n. 1 de 5 de setembro de 2002). Research has clearly shown a strong association between the main non-communicable chronic diseases and a few well-recognized risk factors, in particular, tobacco use, alcohol consumption, obesity, arterial hypertension, high cholesterol levels, low fruit and vegetable consumption, and sedentariness. Monitoring these risk factors and the prevalence of diseases related to them is essential in defining health policies regarding the prevention of such ailments 7,8 .
However, the insufficiency in obtainable information from the national database presently available, regarding the monitoring and evaluation of health conditions and the performance of health systems, which many times are focused on resource allocation and expenditure control, does not allow for necessary analysis of the health outcomes in a population. In this sense, the population health surveys have been used more and more as a means of obtaining, not only information about the diseases, but also about the risk factors and the social determinants of the health/disease process. It is possible to cover a diverse repertoire of health measures through the health surveys, such as health perception, disease and disability occurrences, behavior, lifestyle, access and use of health services, besides a variety of demographic and socioeconomic characteristics, allowing us to explore the relation among different variables. Particularly in relation to chronic diseases, the information obtained through the health surveys complement the insufficient knowledge about its prevalence 9 .

In this context, facing the columns of available information about the reported morbidity, presently, in Brazil, the World Health Survey (WHS), conducted in this country in 2003 as an integrating part of a project by the World Health Organization (WHO), brought relevant data on the population's health state. This populational survey with national representation covers various aspects of the population's health through personal interviews. Among the various researched modules, one was specifically directed to chronic diseases, where the interviewees were questioned about the medically diagnosed presence of six diseases: arthritis, angina, asthma, depression, schizophrenia, and diabetes mellitus. The purpose of this article is to present the profile for the interviewees diagnosed with one of the named diseases according to the following variables: socioeconomic, demographic, treatment and use of medication, and how these individuals evaluated their health condition. These results will then be contrasted with those that have none of these diseases.

\section{Methodology}

\section{Sample}

The sample involved 5,000 individuals 18 years old at least. The sampling was accomplished in two stages. In the first stage, 250 census tracts were selected with a probability proportional to their size. An explicit stratification was done 
according to rural and urban situation and the municipality's size $(<50,000 ; 50,000-399,999$; $400,000+$ population) and an implicit stratification was done according to homeowners' average income, with the purpose of securing socioeconomic differences existent between selected primary units. A random selection of twenty residences was done in each sector. One resident was chosen per domicile to answer questions regarding the residence's characteristics and only one individual, randomly selected, to answer the individual questionnaire.

\section{Fieldwork}

The WHS was done in Brazil from January to September of 2003, subdivided in ten microsurveys under the supervision of local coordinators. For each micro-survey a team was set up composed of four interviewers and one supervisor. Each micro-survey covered 300 to 500 residential interviews distributed through 15 to 25 census tracts.

\section{Questionnaire}

The WHO's original questionnaire was translated and adapted for its application in our environment by the research coordinators and local coordinators. The questionnaire was built with a modular structure covering various domains, as follows: socioeconomic conditions; health condition description; risk factors; individuals health condition (chronic and acute problems); coverage of some health programs; evaluation of health system's response according to the individual; and health expenses by residence, including private health programs.

The questionnaire included a module directed specifically to chronic diseases, once the interviewees were questioned about the presence of a diagnosis for six chronic diseases: arthritis, angina, asthma, depression, schizophrenia, and diabetes mellitus. The WHS's original version was followed for this module's particular case, not including other diseases.

The research was approved by the Ethics in Research Committee of Fundação Oswaldo Cruz.

\section{Data analysis}

Since this constitutes a complex sample, the necessary considerations were used for this type of study, using the SUDAAN application.

To evaluate chronic health situations, six questions were made about the specific problems - arthritis, angina, asthma, depression, schizophrenia, and diabetes, questioning for each one of them: (i) the presence of a diagnosis ("Have you ever been diagnosed with ...?"); (ii) treatment ("Have you ever been treated for ...?"); (iii) and the use of medications in the last two weeks ("Have you taken any medication or other treatment in the last two weeks for ...?"). Those who answered positively to at least one of the diseases were considered carrier of chronic diseases. The criteria for disease selection was not exculpatory, that is, a person could be diagnosed with more than one chronic disease. However, for the purpose of analysis in this article, situations of co-morbidity were not analyzed.

For the evaluation of the health state, individuals were asked how they perceived their own health ("In general, how do you evaluate your present health?"), answering with one of five options: very good, good, moderate, bad, very bad.

The individuals diagnosed with one of the six chronic diseases were analyzed according to age group, gender, education level (incomplete primary schooling, completed primary schooling or more), bad or very bad self-rated health, as well as in accordance with receiving treatment or use of medication in the last fifteen days.

Having in mind that the age variable is strongly associated with the prevalence of chronic diseases, to test the differences according to education level of the diseases' prevalence rate, a model of multiple logistic regression was used, where the presence of a disease remained as a dependent variable while age and education level were independent variables, and where the lowest education level was the reference (fundamental schooling incomplete). The same process was used to compare the proportion of bad or very bad selfevaluation among carriers of chronic diseases. In this case, the logistic regression procedure had poor or very poor self-evaluations as the dependent variable and age and the presence of one of the reported diseases as independent variables.

\section{Results}

Among the 5,000 interviewees, 39.1\% reported a medical diagnosis for at least one of the six analyzed chronic diseases. In relation to the specific problems that were researched, depression was the most prevalent, having been reported by $19.2 \%$ of the interviewees, followed by asthma $(12.0 \%)$, arthritis $(10.5 \%)$, chest angina $(6.7 \%)$, diabetes $(6.2 \%)$, and psychosis or schizophrenia $(1.7 \%)$. In what refers to the age distribution, a significant difference was con- 
firmed in the prevalence rate of all diseases by age, except in relation to bronchial asthma. Depression was the most frequent disease in every age group, affecting $14.5 \%$ of individuals between 18 and 34 years and $23.3 \%$ among those with 50 years or more. However the greatest range of variation was verified in relation to diabetes, varying from $1.4 \%$ to $15.3 \%$ between the more extreme age groups (Table 1).

All chronic diseases were most prevalent among women, with the exception of chest angina. In relation to the differences in prevalence rates by gender, angina and asthma showed no significance, while arthritis and depression pre- sented the greatest variations. Again, depression calls for attention, being the most frequent disease in both genders, affecting $25.1 \%$ of women and $12.3 \%$ of men (Table 2 ).

As we proceed to the evaluation of treatment coverage (anytime in life) and the use of medication (in the last two weeks) for each of the six chronic diseases (Table 3), it is observed that the greatest treatment coverage corresponded to asthma (90.0\%), followed by diabetes $(68.0 \%)$, while the least coverage was for depression (68.0\%). More than $70.0 \%$ of the interviewees reported a treatment for the other diseases, while for the use of medication in the re-

Table 1

Proportion of individuals who reported a medical diagnosis of a chronic disease,

by disease considered in the World Health Survey and age group. Brazil, 2003.

\begin{tabular}{|c|c|c|c|c|c|}
\hline Disease & $\begin{array}{l}\text { Age group } \\
\text { (years) }\end{array}$ & $\mathbf{N}$ & $\begin{array}{l}\text { Proportion (\%) } \\
\text { with diagnosis }\end{array}$ & $\mathrm{Cl} 95 \%$ & $p$-value \\
\hline \multirow[t]{4}{*}{ Arthritis } & $18-29$ & 76 & 3.7 & $2.8-4.6$ & 0.0000 \\
\hline & $30-49$ & 124 & 8.4 & $7.0-9.8$ & \\
\hline & $50+$ & 326 & 22.3 & 20.1-24.7 & \\
\hline & Total & 526 & 10.5 & $9.6-11.5$ & \\
\hline \multirow[t]{4}{*}{ Angina } & $18-29$ & 52 & 2.5 & $1.6-3.4$ & 0.0000 \\
\hline & $30-49$ & 94 & 6.4 & $5.0-7.7$ & \\
\hline & $50+$ & 190 & 13.0 & 10.9-15.1 & \\
\hline & Total & 336 & 6.7 & $5.8-7.6$ & \\
\hline \multirow[t]{4}{*}{ Asthma } & $18-29$ & 255 & 12.4 & $10.6-14.2$ & 0.3108 \\
\hline & $30-49$ & 161 & 10.9 & $9.2-12.6$ & \\
\hline & $50+$ & 185 & 12.7 & $10.8-14.5$ & \\
\hline & Total & 601 & 12.0 & 11.0-13.1 & \\
\hline \multirow[t]{4}{*}{ Depression } & $18-29$ & 298 & 14.5 & $12.5-16.4$ & 0.0000 \\
\hline & $30-49$ & 323 & 21.8 & $19.2-24.4$ & \\
\hline & $50+$ & 340 & 23.3 & $20.7-25.9$ & \\
\hline & Total & 961 & 19.2 & $17.7-20.7$ & \\
\hline \multirow[t]{4}{*}{ Schizophrenia } & $18-29$ & 19 & 0.9 & $0.5-1.3$ & 0.0038 \\
\hline & $30-49$ & 26 & 1.8 & $1.0-2.5$ & \\
\hline & $50+$ & 38 & 2.6 & $1.7-3.5$ & \\
\hline & Total & 83 & 1.7 & $1.2-2.1$ & \\
\hline \multirow[t]{4}{*}{ Diabetes } & $18-29$ & 28 & 1.4 & $0.9-1.8$ & 0.0000 \\
\hline & $30-49$ & 57 & 3.9 & $2.8-4.9$ & \\
\hline & $50+$ & 224 & 15.3 & 13.0-17.7 & \\
\hline & Total & 309 & 6.2 & $5.4-7.0$ & \\
\hline \multirow[t]{4}{*}{ At least one of the 6 diseases } & $18-29$ & 599 & 29.1 & $26.6-31.5$ & 0.0000 \\
\hline & $30-49$ & 563 & 38.0 & $35.2-40.8$ & \\
\hline & $50+$ & 794 & 54.4 & 51.6-57.1 & \\
\hline & Total & 1,956 & 39.1 & $37.3-40.9$ & \\
\hline
\end{tabular}


Proportion of individuals who reported a medical diagnosis of a chronic disease,

by disease considered in the World Health Survey and gender. Brazil, 2003.

\begin{tabular}{|c|c|c|c|c|c|}
\hline Disease & Gender & $\mathbf{N}$ & $\begin{array}{l}\text { Proportion (\%) } \\
\text { with diagnosis }\end{array}$ & $\mathrm{Cl} 195 \%$ & p-value \\
\hline \multirow[t]{3}{*}{ Arthritis } & Female & 347 & 12.8 & $11.5-14.1$ & 0.0000 \\
\hline & Male & 179 & 7.8 & $6.7-9.0$ & \\
\hline & Total & 526 & 10.5 & $9.6-11.5$ & \\
\hline \multirow[t]{3}{*}{ Angina } & Male & 177 & 6.5 & $5.5-7.6$ & 0.5712 \\
\hline & Female & 159 & 6.9 & $5.7-8.2$ & \\
\hline & Total & 336 & 6.7 & $5.8-7.6$ & \\
\hline \multirow[t]{3}{*}{ Asthma } & Male & 341 & 12.6 & $11.3-13.9$ & 0.2683 \\
\hline & Female & 260 & 11.4 & $9.7-13.1$ & \\
\hline & Total & 601 & 12.0 & $11.0-13.1$ & \\
\hline \multirow[t]{3}{*}{ Depression } & Male & 679 & 25.1 & $23.0-27.1$ & 0.0000 \\
\hline & Female & 282 & 12.3 & $10.5-14.1$ & \\
\hline & Total & 961 & 19.2 & $17.7-20.7$ & \\
\hline \multirow[t]{3}{*}{ Schizophrenia } & Male & 56 & 2.1 & $1.5-2.7$ & 0.0146 \\
\hline & Female & 27 & 1.1 & $0.6-1.7$ & \\
\hline & Total & 83 & 1.7 & $1.2-2.1$ & \\
\hline \multirow[t]{3}{*}{ Diabetes } & Male & 191 & 7.0 & $5.9-8.2$ & 0.0133 \\
\hline & Female & 118 & 5.2 & $4, .1-6.2$ & \\
\hline & Total & 309 & 6.2 & $5.4-7.0$ & \\
\hline \multirow[t]{3}{*}{ At least one of the 6 diseases } & Male & 1210 & 44.6 & $42.6-46.8$ & 0.0000 \\
\hline & Female & 746 & 32.5 & $30.0-35.0$ & \\
\hline & Total & 1,956 & 39.1 & $37.3-40.9$ & \\
\hline
\end{tabular}

ported period (two weeks before the interview), the standards were quite different: the greatest percentages corresponded to schizophrenia (54.0\%), angina $(47.0 \%)$, diabetes $(45.0 \%)$, and the smallest, asthma (27.0\%). It is observed that, in general, women use medication more frequently than men, with exceptions such as in the case of diabetes.

A clear trend is verified in Table 4 for a poorer health evaluation among individuals carriers of at least one of the six chronic diseases (15.9\%) when compared to those with no diseases (5.6\%). This difference is still statistically significant after adjusting results for age and gender. The poorest evaluations were reported by individuals diagnosed with psychosis or schizophrenia (28.0\%), chest angina (27.5\%), and arthritis (24.0\%).

Table 5 compares the rates of disease prevalence by education level. A trend for greater prevalence of the analyzed diseases is observed in the group with an incomplete prima- ry schooling compared to those with a complete primary schooling or higher. However, after computing age and gender, these difference only showed themselves statistically significant for schizophrenia and diabetes.

\section{Discussion}

The chronic diseases analyzed in this study represent serious problems in the morbi-mortality profile for Brazil as in many other countries, contributing to the disease burden with high percentages, measured through the DALY indicator. A populational survey taken in eight European countries revealed that $55.1 \%$ of the adult population is a carrier for at least one chronic disease and $30.2 \%$ for more than one disease 10 . Similar results were found in the $\mathrm{Na}$ tional Population Health Survey in Canada 11. Both studies found a larger proportion for the 
Table 3

Treatment coverage and medication use in the last two weeks prior to the survey, by chronic disease considered in the World Health Survey according to gender. Brazil, 2003

\begin{tabular}{|c|c|c|c|}
\hline \multirow[t]{2}{*}{ Disease } & \multirow[t]{2}{*}{ Gender } & \multicolumn{2}{|c|}{ Proportions (\%) } \\
\hline & & $\begin{array}{l}\text { Has been treated } \\
\text { for this disease }\end{array}$ & $\begin{array}{l}\text { Used medication } \\
\text { in the last two weeks }\end{array}$ \\
\hline \multirow[t]{3}{*}{ Arthritis } & Female & 75.2 & 42.9 \\
\hline & Male & 72.8 & 32.4 \\
\hline & Total & 74.4 & 39.4 \\
\hline \multirow[t]{3}{*}{ Angina } & Female & 71.8 & 48.9 \\
\hline & Male & 73.6 & 43.4 \\
\hline & Total & 72.8 & 46.6 \\
\hline \multirow[t]{3}{*}{ Asthma } & Female & 88.8 & 27.9 \\
\hline & Male & 92.3 & 24.6 \\
\hline & Total & 90.3 & 26.5 \\
\hline \multirow[t]{3}{*}{ Depression } & Female & 70.6 & 36.2 \\
\hline & Male & 61.3 & 24.9 \\
\hline & Total & 67.8 & 32.9 \\
\hline \multirow[t]{3}{*}{ Schizophrenia } & Female & 75.0 & 57.1 \\
\hline & Male & 80.8 & 46.2 \\
\hline & Total & 77.1 & 53.7 \\
\hline \multirow[t]{3}{*}{ Diabetes } & Female & 85.2 & 44.7 \\
\hline & Male & 87.1 & 45.2 \\
\hline & Total & 86.2 & 44.9 \\
\hline
\end{tabular}

presence of at least one chronic disease when compared to our data $(39.8 \%)$. With regard to what weighs the demographic profile of these countries, these differences may also have been influenced by the list of evaluated diseases, which differs from country to country.

The validity of self-evaluated morbidity taken in the context of these residential surveys has been questioned by some authors. Sen 12 warns of equivocation resulting from using information based exclusively on the individuals' perception when evaluating needs in medical care, since this information is strongly influenced by each person's social experience. However, health surveys done in various countries have shown that the information obtained on the prevalence of chronic diseases present an acceptable concordance when compared to medical registries and clinical examinations, specially for some selected pathologies, particularly cardiovascular diseases and diabetes mellitus 13,14,15,16,17.

In Brazil, the prevalence for five chronic diseases researched by the health supplement of the National Survey by Residential Sample (PNAD - Pesquisa Nacional por Amostra de Domicílios) conducted in 1998, when compared to estimates taken by the Study of Burden of Disease in Brazil (Carga de Doença no Brasil), showed there were some discrepancies between both estimates 18 . However, the strategies for collecting information were distinct from each other. In relation to the results given by PNAD, the authors themselves call attention to some of its limitations, specially in relation to the use of the respondent proxy. In the WHS's case, the information collected by the individual questionnaires were furnished by the interviewees themselves, and, to minimize bias caused by memory, the existence of a medical diagnosis for the specific health problems was asked for 19 .

The gradient that was detected in the prevalence of diseases, increasing with age, and varying according to gender, with greater prevalence among women for most of the analyzed diseases, and poorer health evaluations among chronic disease carriers, agrees with the aforementioned literature 20 .

Our data regarding to the diagnosis of arthritis were very similar to the data described by other researchers. $25.0 \%$ of the adult population in the United States in 2001 (about 49 million people) recorded a diagnosis for arthritis. Greater prevalence and a gradient related to age $(19.0 \%$ among adults up to 44 years and $58.8 \%$ among those older than 65 ) is verified among women. Besides being highly prevalent, arthritis is associated with elevated rates of disability (17.5\% of American adults), specially in the population with less education. The disability arising from arthritis impacts the economically active North American population since it is one of the main factors associated with work incapacity related to physical activities. These aspects reveal arthritis as one of the main health issues for many countries 4,6,21, $22,23,24$. The Brazilian WHS reveals, similarly, an elevated proportion of poor health self evaluations in this disease group.

Data from the Centers for Disease Control and Prevention (CDC) 25 reveal that $7.5 \%$ of the adult population residing in the United States suffers from asthma, with a reduction in prevalence with age. When considering the diagnosis of chronic bronchitis, the prevalence in the Australian adult population was $12.0 \% 26$, which is very close to the results found by our survey, suggesting a possible influence from the various classifications the population may use to identify the disease. Studies on the disease's perception, the degree in limitation of daily ac- 
Comparison of proportions (\%) of individuals with bad or very bad self-rated health, according to the presence of a chronic disease. Brazil, 2003.

\begin{tabular}{|c|c|c|c|c|c|c|}
\hline \multirow[t]{2}{*}{ Disease } & \multirow[t]{2}{*}{ Presence } & \multirow{2}{*}{$\begin{array}{c}\text { Proportion } \\
(\%) \text { of bad } \\
\text { self-rated health }\end{array}$} & \multicolumn{4}{|c|}{ OR } \\
\hline & & & Brute & p-value & $\begin{array}{l}\text { Adjusted by } \\
\text { age and gender }\end{array}$ & $\mathrm{p}$-value \\
\hline \multirow[t]{2}{*}{ Arthritis } & Yes & 24.00 & 3.90 & 0.0000 & 2.42 & 0.0000 \\
\hline & No & 7.50 & 1.00 & & 1.00 & \\
\hline \multirow[t]{2}{*}{ Angina } & Yes & 27.50 & 4.37 & 0.0000 & 3.04 & 0.0000 \\
\hline & No & 7.90 & 1.00 & & 1.00 & \\
\hline \multirow[t]{2}{*}{ Asthma } & Yes & 13.50 & 1.65 & 0.0003 & 1.59 & 0.0011 \\
\hline & No & 8.60 & 1.00 & & 1.00 & \\
\hline \multirow[t]{2}{*}{ Depression } & Yes & 16.40 & 2.41 & 0.0000 & 2.13 & 0.0000 \\
\hline & No & 7.50 & 1.00 & & 1.00 & \\
\hline \multirow[t]{2}{*}{ Schizophrenia } & Yes & 28.00 & 3.96 & 0.0000 & 3.28 & 0.0001 \\
\hline & No & 8.90 & 1.00 & & 1.00 & \\
\hline \multirow[t]{2}{*}{ Diabetes } & Yes & 23.40 & 3.39 & 0.0000 & 1.91 & 0.0001 \\
\hline & No & 8.30 & 1.00 & & 1.00 & \\
\hline At one of the & Yes & 15.90 & 3.61 & 0.0000 & 2.74 & 0.0000 \\
\hline 6 diseases & No & 5.00 & 1.00 & & 1.00 & \\
\hline
\end{tabular}

Table 5

Comparison of proportions (\%) of individuals diagnosed with one of the six chronic diseases, considered by the World Health Survey according to education level. Brazil, 2003.

\begin{tabular}{|c|c|c|c|c|c|c|}
\hline \multirow[t]{2}{*}{ Disease } & \multirow{2}{*}{$\begin{array}{l}\text { Fundamental } \\
\text { schooling }\end{array}$} & \multirow{2}{*}{$\begin{array}{c}\text { Proportion } \\
\text { with diagnosis } \\
(\%)\end{array}$} & \multicolumn{4}{|c|}{ OR } \\
\hline & & & Brute & $p$-value & $\begin{array}{c}\text { Adjusted by } \\
\text { age and gender }\end{array}$ & $p$-value \\
\hline \multirow[t]{2}{*}{ Arthritis } & Incomplete & 13.50 & 2.13 & 0.0000 & 1.22 & 0.0856 \\
\hline & Complete & 6.80 & 1.00 & & 1.00 & \\
\hline \multirow[t]{2}{*}{ Angina } & Incomplete & 8.50 & 2.01 & 0.0000 & 1.26 & 0.1424 \\
\hline & Complete & 4.40 & 1.00 & & 1.00 & \\
\hline \multirow[t]{2}{*}{ Asthma } & Incomplete & 12.10 & 1.02 & 0.8087 & 1.00 & 0.9809 \\
\hline & Complete & 11.90 & 1.00 & & 1.00 & \\
\hline \multirow[t]{2}{*}{ Depression } & Incomplete & 19.40 & 1.03 & 0.7645 & 0.86 & 0.1111 \\
\hline & Complete & 19.00 & 1.00 & & 1.00 & \\
\hline \multirow[t]{2}{*}{ Schizophrenia } & Incomplete & 2.30 & 2.69 & 0.0005 & 2.23 & 0.0089 \\
\hline & Complete & 0.90 & 1.00 & & 1.00 & \\
\hline \multirow[t]{2}{*}{ Diabetes } & Incomplete & 8.50 & 2.78 & 0.0000 & 1.44 & 0.0329 \\
\hline & Complete & 3.20 & 1.00 & & 1.00 & \\
\hline
\end{tabular}


tivities, and the use of medication reveal that, even though most asthmatics report more symptoms than expected by doctors, they classify their disease as mild or very mild. The use of medical services also relates directly to this medical situation's severity 27,28 . The low rate in medication use found in this study for the reported period may be, in part, due to clinical evolution of this disease.

It was estimated, in Brazil, at the end of the 80 's, about an $8.0 \%$ prevalence of diabetes mellitus among adults (30-69 years) residing in nine Brazilian capitals. Similar results were found more recently in a residential survey on risk behavior and morbidity caused by nontransmittable diseases and problems, done by the National Cancer Institute (INCA - Instituto Nacional de Câncer), taken in fifteen Brazilian capitals and the Federal District between 2002 and 2003, with a rate for the prevalence of diabetes mellitus varying from 5.2 to $9.4 \%$, and significant gains with age while not verifying important differences between gender 29. The WHS's results $-6.9 \%$ rate of prevalence, and the pattern found by age and gender - showed themselves to be coherent with results taken from INCA's recent survey.

European studies have shown that diabetic patients evaluate a poorer state of health and report greater limitations in their activities, due to the disease, when compared to non-diabetics. Also, the existence of socioeconomic inequalities in diabetes mortality has been verified. Patients with lower income and less education present more severe and frequent complications. One explanation for this behavior could be related to medical service accessibility, perception of severity, and adherence to treatment 30,31 . In the present study, important differences were found by education level, with a greater rate in diabetes prevalence among those with an incomplete primary schooling, even after controlling for age and sex.

The low prevalence of angina found in our study may be explained by the high mortality associated with cardiovascular diseases. These constitute the main cause in mortality and disability in developed and developing countries, especially coronary diseases and cerebrovascular diseases. In Brazil, data from 1998 reveal that $24.0 \%$ of the potential years lost by premature death are caused solely by cardiovascular diseases, a close percentage to the $26.0 \%$ found for the set of infectious, maternal, nutritional, and perinatal diseases ${ }^{3}$. Cardiovasular diseases also present a large impact on demand for health services, being responsible for $19.0 \%$ of total hospitalizations registered by the Unified
National Health System (SUS - Sistema Único de Saúde) in 2004, among individuals 20 years or older. $11.4 \%$ of these hospitalizations were due to ischaemic heart diseases (Departamento de Informática do SUS. Morbidade Hospitalar do SUS por Local de Residência - Brasil, 2004. http://tabnet.datasus.gov.br, accessed on $02 / \mathrm{Mar} / 2005)$. In the United States, $40.0 \%$ of deaths are caused by cardiac diseases. Although they are most prevalent in a population over 65 years, attention has been called in this country to the rise in sudden deaths among a younger population (15-34 years) due to these diseases 32 .

One of the most interesting epidemiologic aspects of the coronary cardiac disease is the difference between genders, that is, a greater prevalence among men. Studies have shown that these differences are found as much in the epidemiologic characterization clinical aspects. Among females, symptoms show up later and, in general, are less typical even though the risk factors are the same for both women and men 33,34 . An association is also found between the presence of physical limitation due to angina and elevated mortality rates. Data from the WHS revealed that $28.0 \%$ of angina carriers self-evaluated their health poorly. Self-reports of angina have consistently proven a factor in mortality prediction, independent of differences in age, race, education level, or presence of medical co-morbidities 35 .

The importance of neuropsychiatric disorders, particularly depression, which showed a high prevalence for both genders in this study, had already been emphasized in previous investigations, showing that these problems are at least as much prevalent, or more, than other chronic diseases like arthritis, diabetes, and hypertension 3,36,37. Ten per cent of the American adult population presents some kind of recent disability due to a mental disease (schizophrenia, phobias, depression, and anxiety), and about $24.0 \%$ show some mental disorder in the last 12 months 38 . A study done among 417 psychiatrists, covering demographic characteristics, clinics and treatment for 1,228 patients, revealed that depression was the most common diagnosis (53.7\%) followed by schizophrenia (14.6\%) 39. It is estimated, in Brazil, that $3.0 \%$ of the general population suffers severe and persistent mental disorders and $12.0 \%$ of the population needs some kind of mental health care, be it continual or casual. In 2004, $3.4 \%$ of the total hospitalizations in the SUS services, among individuals older than 20 years, was caused by mental disorders, while schizophrenia was the main cause for these intern- 
ments $(43.0 \%)$ (Departamento de Informática do SUS. Morbidade Hospitalar do SUS por Local de Residência - Brasil, 2004. http:// tabnet.datasus.gov.br, accessed on 02/Mar/2005).

Besides the high prevalence in mental disorders, one characteristic that has been highlighted is the small fraction of patients that actually receive treatment. A revision of articles on population-based research in different countries showed that the percentage difference between the number of individuals that need treatment and the number of individuals that are effectively receiving some kind of therapy (gap treatment) is extremely high, varying from $32.0 \%$ for schizophrenia and other psychosis to $56.0 \%$ for depression, with large variations between countries 40 .

The question of low adherence to treatment among carriers of different chronic diseases has become a worrisome matter for the WHO. This problem has been detected in every situation where the self-administration of medications is necessary, including asthma, hypertension, depression, diabetes, tuberculosis, and AIDS. Adherence to therapy in developed countries is, on average, $50.0 \%$, and can be much less in developing countries when faced with the iniquitous access to health services. The low adherence to long term therapy compromises the treatment's effectiveness, becoming a critical problem in the population's health, be it in regards to the perspective in quality of life or in relation to economic aspects. Adherence to treatment for depression is estimated between 40.0 and $70.0 \%$ and for asthma, $43.0 \%$ for treating critical situations and, $28.0 \%$ for prevention treatment. Adherence to treatment by chronic disease patients reduces complications and disabilities, raising quality and expectancy in life 41 .

Another aspect that must be highlighted is that effective treatment for chronic diseases also requires a change in the type of service offered, from the episodic care to a more active approach, emphasizing long term follow-ups. The barriers health care access must be carefully analyzed and new service models investigated, besides reviewing methods of remuneration that are not only based on the number of consultations but on educational and advisory activities.

Finally, limitations to this study must be pointed out. Because we are speaking of a survey conducted through residential interviews, patients in severe conditions (unable to provide information) and hospitalized patients were excluded. In the case of chronic diseases, which present various degrees of severity, this problem should be accounted for in the evaluation of the diseases' prevalence. However, despite these limitations, it is gradually more necessary to develop regular, periodic, and representative surveys that reflect the true health conditions in the country.

\section{Resumo}

A Pesquisa Mundial de Saúde (PMS), realizada no Brasil em 2003, incluiu questionamento sobre diagnóstico de seis doenças: artrite, angina, asma, depressão, esquizofrenia e diabetes mellitus. Foram selecionados 5 mil indivíduos em 250 setores censitários, por amostragem probabilística. Analisou-se o perfil sócio-demográfico, a cobertura de tratamento e a auto-avaliação de saúde dos indivíduos com diagnóstico de uma dessas doenças, ajustando-se os efeitos de sexo e idade por modelos de regressão logística. A depressão foi a mais prevalente (19,2\%), seguida pela asma (12,0\%), artrite (10,5\%), angina de peito (6,7\%), diabetes $(6,2 \%)$ e esquizofrenia (1,7\%), sendo que $39,1 \%$ referiram diagnóstico médico de pelo menos uma. Fo- ram encontradas diferenças significativas por idade, exceto para asma. Todas as doenças foram mais prevalentes entre as mulheres, exceto angina. A taxa de diabetes foi significativamente maior entre os de menor grau de instrução. Conclui-se que as seis doenças apresentam comportamento diferenciado em relação à cobertura de tratamento. Porém, no que se refere à percepção da própria saúde, comparando-se os portadores de qualquer uma das seis doenças em relação aos demais, a avaliação foi bem pior, mesmo após ajuste por idade e sexo.

Nível de Saúde; Doença Crônica; Cobertura de Serviços de Saúde 


\section{Contributors}

M. M. Theme-Filha delineated the article's content, participated in the data's statistical analysis and was responsible for writing most of the text. C. L. Szwarcwald discussed the results, participated in the text's writing and coordinated the research. P. R. B. SouzaJúnior participated in the data's statistical analysis.

\section{Acknowledgements}

The present study had financial support from the World Health Organization, the National Council for Scientific and Technologic Development (Conselho Nacional de Desenvolvimento Científico e Tecnológico) and the Department of Health's Science and Technology Department (Departamento de Ciência e Tecnologia do Ministério da Saúde).

\section{References}

1. Gaylin DS, Kates J. Refocusing the lens: epidemiologic transition theory, mortality differentials, and the AIDS pandemic. Soc Sci Med 1997; 44:60921.

2. Omran AR. The epidemiologic transition: a theory of de epidemiology of population change. Bull World Health Organ 2002; 79:161-70.

3. Schramm JMA, Oliveira AF, Leite IC, Valente JG, Gadelha AMJ, Portela MC, et al. Transição epidemiológica e o estudo de carga de doença no Brasil. Ciênc Saúde Coletiva 2004; 9:897-908.

4. Burton WN, Pransky G, Conti DJ, Chen CY, Edington DW. The association of medical conditions and presenteeism. J Occup Environ Med 2004; 46(6 Suppl):S38-45.

5. Wang PS, Beck A, Berglund P, Leutzinger JA, Pronk N, Richling D, et al. Chronic medical conditions and work performance in the health and work performance questionnaire calibration surveys. J Occup Environ Med 2003; 45:1303-11.

6. Kessler RC, Greenberg PE, Mickelson KD, Meneades LM, Wang PS. The effects of chronic medical conditions on work loss and work cutback. J Occup Environ Med 2001; 43:218-25.

7. Monteiro CA, Moura EC, Jaime PC, Lucca A, Florindo AA, Figueiredo IC, et al. Monitoramento de fatores de risco para doenças crônicas por entrevistas telefônicas. Rev Saúde Pública 2005; 39:4757.

8. Nissinen A, Berrios X, Puska P. Community-based noncommunicable disease interventions: lessons from developed countries for developing ones. Bull World Health Organ 2001; 79:963-70.

9. Viacava F. Informações em saúde: a importância dos inquéritos populacionais. Ciênc Saúde Coletiva 2002; 7:607-21.

10. Alonso J, Ferrer M, Gandek B, Ware Jr. JE, Aaronson NK, Mosconi P, et al. Health-related quality of life associated with chronic conditions in eight coutries: results from the International Quality of Life Assessment (IQOLA) Project. Qual Life Res 2004; 13:283-98.

11. Iron KS, Manuel DG, Williams J. Using a linked data set to determine the factors associated with utilization and costs of family physician services in Ontario: effects of self-reported chronic conditions. Chronic Dis Can 2003; 24:124-32.
12. Sen A. Health: perception versus observation. BMJ 2002; 324:860-1.

13. Haapanen N, Miilunpalo S, Pasanen M, Oja P, Vuori L. Agreement between questionnaire data and medical records of chronic diseases in middle-aged and elderly Finnish men and women. Am J Epidemiol 1997; 145:762-9.

14. Wu SC, Li CY, Ke DS. The agreement between selfreporting and clinical diagnosis for selected medical conditions among elderly in Taiwan. Public Health 2000; 114:137-42.

15. Ferraro KF, Su Y. Physician-evaluated and self-reported morbidity for predicting disability. Am J Public Health 2000; 90:103-8.

16. Beckett M, Weinstein M, Goldman N, Yu-Hsuan L. Do health interview surveys yield reliable data on chronic illness among older respondents? Am J Epidemiol 2000; 151:315-23.

17. Molarius A, Janson S. Self-rated health, chronic diseases, and symptoms among middle-aged and elderly men and women. J Clin Epidemiol 2002; 55:364-70.

18. Leite IC, Schramm JMA, Gadelha AMJ, Valente JG, Campos MR, Portela MC, et al. Comparação das informações sobre as prevalências de doenças crônicas obtidas pelo suplemento saúde da PNAD/ 98 e as estimadas pelo estudo Carga de Doença no Brasil. Ciênc Saúde Coletiva 2002; 7:733-41.

19. Bruin A, Picavet HSJ, Nossikov A. Health Interview Surveys: towards international harmonization of methods and instruments. Geneva: World Health Organization; 1996. (World Health Organization Regional Publications, European Series 58).

20. Almeida MF, Barata RB, Monteiro CV, Silva ZP. Prevalência de doenças crônicas auto-referidas e utilização de serviços de saúde, $\mathrm{PNAD} / 1998$, Brasil. Ciênc Saúde Coletiva 2002; 7: 743-56.

21. National Center for Chronic Disease Prevention and Health Promotion, Centers for Disease Control and Prevention. Arthritis: the nation's leading cause of disability. http://www.cdc.gov/nccdphp/ bb_arthritis/index.htm (accessed on 05/Jan/2005).

22. Fontaine KR, Heo M, Bathon J. Are US adults arthritis meeting public heath recommendations for physical activity? Arthritis Rheum 2004; 50: 624-8. 
23. Seavey WG, Kurata JH, Cohen RD. Risk factors for incident self-reported arthritis in a 20 year follow-up of the Alameda County Study Cohort. J Rheumatol 2003; 30:2103-11.

24. Kaplan MS, Huguet N, Newsom JT, McFarland BH. Characteristics of physically inactive older adults with arthritis: results of populations-based study. Prev Med 2003; 37:61-7.

25. Centers for Disease Control and Prevention. Asthma prevalence and control characteristics by race/ethnicity - United States, 2002. MMWR Morb Mortal Wkly Rep 2004; 53:145-8.

26. Abramson M, Matheson M, Wharton C, Sim M, Walters EH. Prevalence of respiratory symptoms related to chronic obstructive pulmonary disease and asthma among middle aged and older adults. Respirology 2002; 7:325-31.

27. Stallberg B, Nystrom KU, Olsson P, Gottberg L, Ronmark E, Lundback B. Living with asthma in Sweden - the ALMA study. Respir Med 2003; 97:835-43.

28. Tinkelman DG, McClure DL, Lehr TL, Schwartz AL. Relationships between self-reported asthma utilization and patient characteristics. J Asthma 2002; 39:729-36.

29. Secretaria de Vigilância em Saúde, Ministério da Saúde/Instituto Nacional de Câncer. Inquérito domiciliar sobre comportamentos de risco e morbidade referida de doenças e agravos não transmissíveis: Brasil, 15 capitais e Distrito Federal, 2002-2003. Rio de Janeiro: Instituto Nacional de Câncer; 2004.

30. Bachman MO, Eachus CD, Hopper G, Davey Smith G, Propper C, Pearson NJ, et al. Socio-economic inequalities in diabetes complications, control, attitudes and health service use: a cross-sectional study. Diabet Med 2003; 20:921-9.

31. Gulliford MC, Mahabir D, Rocke B. Diabetes-related inequalities in health status and financial barriers to health care access in a populationbased study. Diabet Med 2003; 21:45-51.
32. National Center for Chronic Disease Prevention and Health Promotion, Centers for Disease Control and Prevention. Preventing heart disease and stroke. http://www.cdc.gov/nccdphp/bb_heartdisease/index.htm (accessed on 02/Mar/2005).

33. Bello N, Mosca L. Epidemiology of coronary heart disease in women. Prog Cardiovasc Dis 2004; 46:287-95.

34. DeVon HA, Zerwic JJ. The symptons of instable angina: do women and men differ? Nurs Res 2003; 52:108-18.

35. Mozaffarian D, Bryson CL, Spertus JA, McDonell MB, Fihn SD. Anginal symptons consistently predict total mortality among outpatients with coronary artery disease. Am Heart J 2003; 146:1015-22.

36. Mathers CD, Vos ET, Stevenson CE, Begg SJ. The burden of disease and injury in Australia. Bull World Health Organ 2001; 79:1076-84.

37. World Health Organization. Prevalence, severity and unmet need for treatment of mental disorders in the World Health Organization World Mental Surveys. JAMA 2004; 291:2581-90.

38. Centers for Disease Control and Prevention. Selfreported frequent mental distress among adults United States, 1993-1996. MMWR Morb Mortal Wkly Rep 1998; 47:325-31.

39. Pincus HA, Zarin DA, Tanielian TL, Johnson JL, West JC, Pettit AR, et al. Psychiatric patients and treatments in 1997: findings from the American Psychiatric Practice Research Network. Arch Gen Psychiatry 1999; 56:441-9.

40. Kohn R, Saxena S, Levav I, Saraceno B. The treatment gap in mental health care. Bull World Health Organ 2004; 82:858-64.

41. World Health Organization. Poor adherence to long-term treatment of chronic diseases is a worldwide problem. Rev Panam Salud Pública 2003; 14:218-21.

Submitted on 04/May/2005

Final version resubmitted on 03/Oct/2005

Approved on 10/Oct/2005 